\title{
Epidemiology of vaccine hesitancy in the United States
}

\author{
Mariam Siddiqui', Daniel A Salmon², and Saad B Omer ${ }^{1, *}$
}

'Emory University; Rollins School of Public Health; Atlanta, GA USA; ${ }^{2}$ Johns Hopkins University; Bloomberg School of Public Health; Baltimore, MD USA

Keywords: vaccines, vaccine hesitancy, immunizations, exemptions, parent beliefs, attitudes

Vaccines are among the most effective public health interventions against infectious diseases. However, there is evidence in the United States for parents either delaying or refusing recommended childhood vaccination. Exemptions to school immunization laws and use of alternative schedule from those recommended by the Advisory Committee on Immunization Practices and the American Academy of Pediatrics cannot only increase the risk of children contracting vaccinepreventable diseases but also increases the risk of infecting others who are either too young to be vaccinated, cannot be vaccinated for medical reasons or did not develop a sufficient immunological response to the vaccine. Healthcare providers are cited as the most influential source by parents on vaccine decision-making. Vaccine hesitancy needs to be addressed by healthcare providers and the scientific community by listening to the parental concerns and discussing risks associated with either delaying or refusing vaccines.

\section{Introduction}

Vaccines are considered one of the most successful public health interventions of the 20th century in combating infectious diseases. ${ }^{1}$ In the United States, high immunization coverage has been responsible for preventing morbidity, mortality and providing substantial cost savings against infectious diseases such as smallpox, measles, polio, diphtheria, pertussis, varicella and hemophilus influenzae type b. For example, routine childhood immunizations in the 2009 birth cohort are estimated to have prevented 20 million cases and 42000 deaths with a savings of $\$ 14$ billion in directs costs and $\$ 69$ billion in societal costs. ${ }^{2}$ However, previous confidence in vaccines is deteriorating with some identifying a vaccine "crisis of public confidence." $3-5$

\section{Reasons for Vaccine Hesitancy}

Vaccine hesitancy has been around as long as we have had vaccines. The remarkable discovery of Smallpox vaccination was met with considerable hesitancy and outright opposition. As was the case when smallpox vaccine was introduced, there are many reasons why portions of the public are hesitant toward vaccination.

*Correspondence to: Saad B Omer; Email: somer@emory.edu Submitted: 09/03/2013; Revised: 11/11/2013; Accepted: 11/18/2013

http://dx.doi.org/10.4161/hv.27243
In the early 19th century there were concerns ranging from connotations of bestiality associated with injecting material from a cow into people, questions regarding the appropriate role of man to intrude on divine will to cause disease, and the optimal balance of individual freedom vs. collective responsibility with compulsory vaccination. In today's world, smallpox has been eradicated due to a successful vaccination program and vaccines have effectively controlled many other significant causes of morbidity and mortality. Consequently, fear has shifted from many vaccine-preventable diseases to fear of the vaccines ${ }^{6}$

Many sociocultural changes have contributed to vaccine hesitancy. ${ }^{4,7}$ Trust in large corporations that manufacture vaccine and the government that widely purchases and promotes vaccines are at all-time low levels. Fear of the "pharmaceutical industrial complex" and inappropriate relationships between industry and the government, distrust in science and the medical community has fueled vaccine hesitancy among portions of the public 5,8 Growing public interest in "natural" products and alternative types of medicines have led to marches to "green our vaccines." While very strong support from pediatricians and health care providers for vaccines has been central to our successes in immunization programs, ${ }^{9-11}$ the medical model has substantively changed over the years. Many parents no longer want to be told what to do for the health of their children by their pediatrician, but rather want a shared decision-making process. ${ }^{5}$ Pediatricians and other healthcare providers are increasingly under pressure to see more patients in less time and find themselves confronted with parents that find misinformation and poor science on the internet. Further, they are finding it increasingly more difficult to effectively communicate accurate and objective information to parents about vaccines and addressing their specific concerns. ${ }^{12-14}$ Efforts have been made to provide additional tools to healthcare providers but the problem is far from solved. In our electronic age, vaccine safety scares rapidly cross national borders and circle the globe. ${ }^{15}$

Vaccines are not only victims of their own success, but also struggle to maintain public confidence given the heuristics that often influence risk perceptions and decision-making. As described by Ball et al., ${ }^{16}$ there is often a "compression" bias which causes people to over-estimate the frequency of rare risks such as those associated with vaccination. "Ambiguity aversion" influences people to favor known risks such as those from diseases rather than unknown risks that are less frequent such as the possibility for vaccine adverse reactions. Further, there is a preference for "natural risks" (disease) over "manmade risks" 
(vaccination). There is a preference for "errors of omission" (risks of not vaccinating) over "errors of commission" (risks of vaccination). Reports of vaccine adverse events are often distorted and amplified through sensationalistic media coverage and rapid dissemination of misinformation on the internet. Therefore, events that are "accessible" can lead to an over-estimation of frequency. When considering the risks and benefits of vaccination, the "compression" heuristic leads to an over-estimation of rare risks such as vaccine adverse reactions and an under-estimation of frequent risks such as those from many vaccine preventable diseases. Together, these heuristics add to the challenge of maintaining public confidence in vaccines.

\section{Trends in Immunization Refusal and Vaccine Hesitancy}

Laws mandating vaccines for school entrance are state based. Hence, there is substantial variability in the laws across the country based on coverage of school grades, vaccines included, introduction of new vaccines, reasons for exemptions, and procedure for granting these exemptions. Mandatory immunization laws for school entrance were designed to control outbreaks of vaccine preventable diseases such as smallpox and measles. ${ }^{17}$ However, certain exemptions are permitted to school entrance immunization laws in each state. Exemptions are provided for medical, philosophical or personal beliefs, and religious reasons. All states permit medical exemptions for individuals who are immunocompromised, allergic to the vaccine or its components, or have medical contraindication to vaccinations. ${ }^{18}$ Healthcare providers typically approve medical exemptions to state immunization laws. In contrast, religious and philosophical or personal belief exemptions are typically granted for reasons related to individual choice rather than medical or scientific evidence. Forty-eight states, all besides Mississippi and West Virginia, permit religious exemptions while only 20 states permit philosophical or personal belief exemptions. ${ }^{18}$

There in substantial variability in the way states implement non-medical exemptions i.e., religious and philosophical or personal belief exemptions. Some states require a parent's signature on a form downloadable from the Internet with pre-specified reasons for seeking exemption while other states require extra effort from the parent by either obtaining the exemption form from the local health department, approval of a local health department official in the form of a letter or signature, notarization, annual renewal and/or a letter of statement from the parent stating the reasons for claiming an exemption. Easy exemption procedures have been associated with increased rates of claiming an exemptions. ${ }^{19}$ Easy exemption procedures and availability of philosophical or personal belief exemptions have been associated with the incidence of pertussis. ${ }^{20,21}$ Increase in non-medical exemptions has accelerated in recent years. Between 2004 and 2011, the mean state-level rate of non-medical exemption increased from $1.48 \%$ to $2.2 \% .^{20,21}$ While this rate seems relatively low, statelevel rates fail to consider geographical clustering of exemptions. For example, during 2011-2012 school year, Washington State had a state-level non-medical exemption rate of $4.2 \%,{ }^{22}$ however, county-level rates ranged from $<1 \%$ to $26 \% .^{23}$ The clustering of exemptions has been quantified in other states as well and was shown to be associated with pertussis outbreaks. ${ }^{22,24}$

\section{Public and Parental Attitudes toward Vaccines}

\section{Perception of vaccine exemptors and hesitant parents}

It is important to understand who refuses vaccines and for what reasons. Smith et al. used the National Immunization Survey from 1995 through 2001 to characterize infants who received no routine childhood immunizations. ${ }^{25}$ Unvaccinated infants were more likely to be male, white, with married mothers of age $\geq 30 \mathrm{y}$, college educated, living in households with an annual income $\geq \$ 75000$ and with $\geq 4$ children compared with vaccinated infants. Other studies have characterized unvaccinated children belonging to families intentionally refusing vaccines with similar demographic characteristics. ${ }^{9,26-30}$

There are several reasons for parents claiming non-medical exemptions to routine childhood immunizations for school entry. A case-control study of unvaccinated children claiming nonmedical exemption reported significantly lower perceived vaccine safety $(61 \%$ vs. $15 \%)$ and efficacy $(54 \%$ vs. $17 \%)$, lower perceived disease susceptibility ( $58 \%$ vs. $15 \%)$ and severity $(51 \%$ vs. $18 \%$ ), and low trust in the government ( $40 \%$ vs. $23 \%$ ) compared with vaccinated children. ${ }^{31}$ Reasons relating to perceived vaccine safety most often cited by parents were vaccines causing harm (69\%) and overloading of the child's immune system (49\%). Further, parents of unvaccinated children were 4 times more likely to use services of alternative medicine providers such as a chiropractor or an acupuncturist. ${ }^{31}$ Other studies have reported similar findings on parental perceptions to routine childhood immunizations. ${ }^{29,31-36}$

National Immunization Survey classified parents into different categories of vaccine doubt indicators to understand their concerns regarding vaccine safety. ${ }^{9}$ Parents were classified asunsure (accepted the vaccine but were not certain if it was the best thing to do), delayed (delayed vaccines for their child), and refused (refusing vaccination of their child altogether). Unsure and refused parents indicated varicella vaccine as causing the most doubt regarding safety and efficacy. These parents believed in inducing natural immunity to varicella infection rather than an artificially induced immunity with vaccines. The other vaccine that caused most doubt was MMR among all categories of parents.

To assess parent's trust in vaccine information received from different sources, Freed et al. administered online surveys in a nationally representative sample of parents with children less than $18 \mathrm{y}$ of age. ${ }^{33}$ The main outcome of the study was credibility in the source of vaccine safety information used by parents. Parents in the study reported that they most often trusted their child's pediatrician for safety information (76\%), followed by other healthcare providers $(26 \%)$, government vaccine experts (23\%), and family and friends (15\%)..$^{33}$ At least $26 \%$ of the parents had placed some trust in celebrities. Seventy-three percent of the parents placed at least some trust in other parents who believed that their child was harmed by a vaccine. Further, there 
were gender differences among parents. Women were more likely than men to place at least some trust in parents claiming a vaccine hurt child, as well as celebrities, television shows, magazines and news articles for vaccine safety.

Kennedy et al. used data from the 2010 HealthStyles survey of consumers to examine confidence in vaccines and hesitancy to use routine childhood immunizations. ${ }^{37}$ This cross-sectional study examined attitudes, beliefs and behaviors of parents of children 6 y or younger. Only 5\% of surveyed parents intended to vaccinate their children with some, but not all of the recommended vaccine and $2 \%$ did not intend to vaccinate their children with any vaccines. ${ }^{37}$ Although, majority of the parents either already vaccinated or intended to vaccinate their child fully, they still reported concerns regarding vaccines. They were less likely expected by chance to report having any of the concerns highlighted in the survey when compared with parents reporting their child to receive some of the recommended vaccines. In contrast, parents intending their child to receive some of the routine childhood vaccines were more likely expected by chance to believe that children received too many vaccines in the first two years of life and that vaccines may cause learning disabilities, such as autism, than parents who already vaccinated or intended to fully vaccinate their children. ${ }^{37}$ The survey further indicated the importance of healthcare providers in building confidence regarding safety of vaccines.

Similarly, a survey commissioned by the Association of State and Territorial Health Officials (ASTHO) explored characteristics of parents who refuse vaccines and reasons for their refusal, effective messages for addressing their resistance, and information sources that are most trusted and influential. ${ }^{32}$ The study results were consistent with other studies regarding parental concerns about vaccine safety. In the sampled population, $16 \%$ refused vaccines while $13 \%$ delayed a vaccine. Effective messages with negative and positive tones were tested for addressing resistance to vaccines. Positive messages regarding vaccines were more effective in disseminating information to vaccine refusers when compared with negative messages. Positive message such as, "vaccination is one of the most important ways you can protect your child from life-threatening illness, offering the best-known protection against a number of diseases" was rated as most compelling among parents. However, negative vaccine messages rated as most compelling among parents were related with risk of adverse effects such as, "vaccines can cause serious health problems, like auto-immune disorders, asthma or autism," "vaccines are unsafe due to ingredients such as thimerosal or aluminum" and "too many vaccines given too soon can harm children.” Demographic characteristics of vaccine refusers were consistent with previous studies (i.e., better educated, high household income, and geographically located in the Pacific states [CA, OR, WA]). However, there was a higher proportion of African-America respondents who reported concerns regarding vaccines. Parents with major vaccine concerns were most concerned about vaccine safety and felt the government does not take these concerns seriously. Further, pediatricians were considered as the most influential source for vaccine information.
Instead of refusing vaccines, some parents are opting for alternative vaccination schedules for their children instead of the recommended schedules by the Advisory Committee on Immunization Practices (ACIP) and the American Academy of Pediatrics (AAP). Alternative vaccination schedules offer delaying receipt of some vaccines or doses, selective avoidance of some vaccines, and limiting the number of vaccinations received by children at any visit to the physician's office. Dr Stephanie Cave and Dr Robert Sears popularized alternative vaccination schedules with the publication of their books in 2001 and 2007 respectively. ${ }^{38,39}$ Wightman et al. surveyed pediatricians in Washington State regarding the frequency of requests by parents for alternative vaccination schedules and the comfort and willingness of pediatricians in using them. ${ }^{40}$ Pediatricians reported frequent requests for alternative vaccination schedules and $61 \%$ were comfortable using an alternative schedule if requested by the parents while prioritizing specific vaccines over others. ${ }^{40} \mathrm{~A}$ retrospective analysis on children born between 2003 and 2009 in Portland, Oregon assessed the trends in uptake of alternative immunization suggesting an increase in the use of alternative schedules. ${ }^{41}$ The number of children with no more than 2 vaccine injections during all immunization visits increased from 2.5 to $9.5 \%$ during 2006 and 2009 for newborns and children 9 mo of age. ${ }^{41}$ When compared with children whose immunizations were on time or occasionally delayed, children consistently limiting immunizations by 9 mo of age had received fewer injections (6.4 vs.10.4) but had more visits when immunizations were administered (4.2 vs. 3.3). ${ }^{41}$ Impact of delaying vaccines on incidence of vaccinepreventable diseases has not been studied widely.

Delaying receipt of vaccines might increase the susceptibility of children by exposing them to vaccine-preventable diseases. Alternative vaccine schedules have become popular; however, the safety or effectiveness of these schedules has not been rigorously studied. ${ }^{42}$ Glanz et al., in a retrospective matched cohort study, examined undervaccination trends in children 2 to 24 mo of age and the healthcare utilization rates between undervaccinated and age-appropriate vaccinated children. ${ }^{43}$ Of the study cohort born between 2004 and 2008, 48.7\% of children were undervaccinated for at least $1 \mathrm{~d}$ before the age of 24 mo and $13 \%$ of children were undervaccinated. Across the birth cohort, prevalence and specific patterns of undervaccination significantly increased over time. Healthcare utilization patterns were different among undervaccinated and age-appropriately vaccinated children. Those undervaccinated for any reason had lower outpatient visits and higher inpatient and emergency department visits in comparison to children age-appropriately vaccinated. However, children undervaccinated due to parental choice had lower outpatient and emergency department visits with no significant difference in inpatient visits when compared with children vaccinated ageappropriately. Delaying vaccines or using alternative immunization schedules not recommended by the ACIP increases the risk of children contracting vaccine-preventable disease and further threatens the maintenance of herd immunity of the community by spreading the disease. The Institute of Medicine report reiterates the safety of routine childhood immunization schedules by 
extensively reviewing concerns from stakeholders, the scientific literature and continuous evaluation of existing data systems. ${ }^{42}$

\section{Why Vaccine Hesitancy Matters}

\section{Vaccine refusal and outbreak of disease}

\section{Individual level risks}

Increasing prevalence of non-medical exemptions in the US to immunization laws has increased the risk of not only acquiring but transmitting vaccine-preventable diseases in children. A retrospective cohort study on nationwide surveillance data from 1985 through 1992 demonstrated that the relative risk of contracting measles was 35 times (95\% CI: 34-37) higher among children whose parents claimed a non-medical exemption compared with vaccinated children..$^{44} \mathrm{~A}$ retrospective study based on data from Colorado, between 1987 through 1998, demonstrated increase in philosophical exemptions over the years with vaccine exemptors at 22.2 times (95\% CI: 15.9-31.1) higher risk of acquiring measles and 5.9 times (95\% CI: 4.2-8.2) higher risk of acquiring pertussis than children who were vaccinated. ${ }^{45}$

Vaccine refusal and occurrence of diseases has been studied in defined pediatric cohorts of Kaiser Permanente health plans to validate the previous finding on increasing individual risk associated with vaccine exemptions. A case-control study in children between 1996 through 2007 demonstrated that vaccine exemptors had 22.8 times (95\% CI: 6.7-7.5) higher risk of pertussis infection compared with vaccinated children, and 11\% (95\% CI: $5.8 \%-16 \%)$ of the pertussis cases were attributed to vaccine refusal. ${ }^{26}$ Similarly, varicella and pneumococcal conjugate vaccine exemptors had 8.6 times (95\% CI: 2.2-33.3) and 6.5 times (95\% CI: 1.7-24.5) higher risk of varicella and pneumococcal/ lobar pneumonia infection respectively compared with children who accepted these vaccines. ${ }^{46,47}$

\section{Community level risks}

In Colorado, frequencies of exemption to immunization laws in a county were significantly associated with the county-level incidence of measles (RR 1.6, 95\% CI: 1.0-2.4) and pertussis (RR 1.9, 95\% CI: 1.7-2.1) cases in children..$^{45}$ Schools reporting measles and pertussis outbreaks had higher number of vaccine exemptors. In addition, vaccine exemptors transmitted the infection not only to other exempt but also to vaccinated children. For example, $42 \%$ of exemptors and $11 \%$ of vaccinated children contracted infection from vaccine exemptors. Salmon et al. used a mathematical model to demonstrate that higher the number of exempt individuals in a population, greater the effect they will have on vaccinated individuals. ${ }^{44}$ According to the model, if the number of exemptors doubled in population and the degree of mixing between the exempt and vaccinated individuals is assumed to be $20 \%, 40 \%$, and $60 \%$ respectively then the incidence of measles infection among vaccinated individuals would increase by $5.5 \%, 18.6 \%$, and $30.8 \%$, respectively. ${ }^{44}$

In a national study by Omer et al., state policies on immunizations were associated with incidence of pertussis in individuals $18 \mathrm{y}$ and younger. ${ }^{20}$ Between 1984 and 2004, after adjusting for demographics in multivariate analysis, pertussis incidence was 1.48 times (95\% CI: 1.03-2.13) higher for states allowing personal belief exemption when compared with states only offering religious exemptions. ${ }^{20}$ In addition, states with easy procedures for granting exemption policies had 1.53 times (95\% CI: 1.10-2.14) higher incidence of pertussis when compared with states with difficult procedures for obtaining exemptions. ${ }^{20}$

Geographical clustering of non-medical exemptions in Michigan was highly correlated with clusters of reported pertussis cases. ${ }^{48}$ Vaccine exemption clusters were 2.7 times (95\% CI: 2.3-3.3) more likely to be in a census tract and included in a pertussis cluster, after adjusting for demographic variables, despite high state-level coverage for pertussis vaccination. ${ }^{48}$

High immunization coverage for measles vaccine was successful in eliminating endemic transmission of measles from United States in $2000 .{ }^{49}$ However, in the post-elimination era of measles, 38 outbreaks were reported with the 3 largest ones occurring among individuals claiming philosophical or personal belief exemptions from 2001 through $2008 .^{50}$ The outbreak resulted from a single importation case spreading among clusters of intentionally unvaccinated children. ${ }^{30}$ A total of 839 persons were exposed, with additional 9 cases in children with philosophical or personal belief exemption, and 3 cases in children too young to be vaccinated. The cost of containing the outbreak was estimated at $\$ 176980$ to public health agencies, medical systems and families. To sustain measles elimination in Unites States it is critical to maintain high vaccination coverage in the community to prevent measles outbreak and especially protect those from contracting the disease who are either too young to be vaccinated and with medical contraindication to vaccines.

\section{Medical exemptions}

Vaccine mandates in all 50 US states allow medical exemptions to school immunizations however, their inappropriate use can result in medical complications and life-threatening illnesses. ${ }^{51}$ Medical exemptions to kindergarten entry requirements have increased from 2004 through 2011. ${ }^{52}$ Rates of medical exemptions was higher for states with easy (adjusted IRR: 6.4, 95\% CI: 2.7-15.6) and medium (adjusted IRR: 4.4, 95\% CI: 1.4-4.4) exemption criteria for medical reasons, and for states with difficult criteria for claiming non-medical exemptions. ${ }^{52}$ This calls for continuous monitoring and evaluation of medical exemptions. Otherwise, easier processes for obtaining medical exemptions can create pockets of susceptible individuals in a population and can disrupt the herd immunity for vaccine-preventable diseases.

\section{Addressing Vaccine Hesitancy}

Substantial gains have been made in combating infectious diseases with the implementation of immunization laws in the United States ensuring that all children are covered by routine childhood vaccines. However, these gains in reducing vaccinepreventable diseases are threatened with shift in perceptions of disease experience and heightened concerns regarding vaccine safety. Vaccine hesitancy is driven by several factors that can influence vaccine uptake. Increased efforts are required to improve and maintain public confidence in vaccines. A rigorous vaccine safety system that takes advantage of new technologies and new scientific methods along with effective communication 
approaches to address vaccine concerns is key to maintaining public confidence. Evidence based interventions to reduce vaccine hesitancy need to be developed and rigorously evaluated. ${ }^{53}$ Particularly useful would be tools to assist clinicians in effectively working with parents who have vaccine concerns. ${ }^{54}$ Messaging to parents must be tailored to meet individual needs as there is considerable variability in the specific issues of concern as well as the types of messages which would be effective. Further, vaccine education tools along with guidance from professional authorities like the ACIP and AAP can help providers overcome their own doubts regarding the safety and effectiveness of routine childhood immunizations. This is important as there is a need for communication of a unified message from healthcare providers to parents on the benefits of vaccines and their timely uptake in children. Ongoing surveillance of trends in vaccine hesitancy can offer valuable insights on interventions that work and can inform the implementation of new preventive measures.

\section{Disclosure of Potential Conflicts of Interest}

No potential conflicts of interest were disclosed.

\section{References}

1. Centers for Disease Control and Prevention (CDC). Ten great public health achievements--United States, 1900-1999. MMWR Morb Mortal Wkly Rep 1999; 48:241-3; PMID:10220250

2. Zhou F. Economic Evaluation of the Routine Childhood Immunization Schedule In the United States. 45th National Immunization Conference Washington DC, 2011.

3. Black S, Rappuoli R. A crisis of public confidence in vaccines. Sci Transl Med 2010; 2:mr1; PMID:21148125; http://dx.doi.org/10.1126/ scitranslmed.3001738

4. Larson HJ, Cooper LZ, Eskola J, Katz SL, Ratzan S. Addressing the vaccine confidence gap. Lancet 2011; 378:526-35; PMID:21664679; http://dx.doi. org/10.1016/S0140-6736(11)60678-8

5. Cooper LZ, Larson HJ, Katz SL. Protecting public trust in immunization. Pediatrics 2008; 122:149 53; PMID:18595998; http://dx.doi.org/10.1542/ peds.2008-0987

6. Chen RT, Hibbs B. Vaccine safety: current and future challenges. Pediatr Ann 1998; 27:445-55; PMID:9677616

7. Larson H, Brocard Paterson P, Erondu N. The globalization of risk and risk perception: why we need a new model of risk communication for vaccines. Drug Saf 2012; 35:1053-9; PMID:23061781

8. Poland GA, Jacobson RM, Ovsyannikova IG. Trends affecting the future of vaccine development and delivery: the role of demographics, regulatory science, the anti-vaccine movement, and vaccinomics. Vaccine 2009; 27:3240-4; PMID:19200833; http://dx.doi. org/10.1016/j.vaccine.2009.01.069

9. Gust DA, Darling N, Kennedy A, Schwartz B. Parents with doubts about vaccines: which vaccines and reasons why. Pediatrics 2008; 122:718 25; PMID:18829793; http://dx.doi.org/10.1542/ peds.2007-0538

10. Salmon DA, Pan WK, Omer SB, Navar AM, Orenstein W, Marcuse EK, Taylor J, deHart MP, Stokley S, Carter T, et al. Vaccine knowledge and practices of primary care providers of exempt vs. vaccinated children. Hum Vaccin 2008; 4:28691; PMID:18424918; http://dx.doi.org/10.4161/ hv.4.4.5752

11. Smith PJ, Kennedy AM, Wooten K, Gust DA, Pickering LK. Association between health care providers' influence on parents who have concerns about vaccine safety and vaccination coverage. Pediatrics 2006; 118:e1287-92; PMID:17079529; http:// dx.doi.org/10.1542/peds.2006-0923

12. Fredrickson DD, Davis TC, Arnould CL, Kennen EM, Hurniston SG, Cross JT, Bocchini JA Jr Childhood immunization refusal: provider and parent perceptions. Fam Med 2004; 36:431-9; PMID:15181556

13. Freed GL, Clark SJ, Hibbs BF, Santoli JM. Parental vaccine safety concerns. The experiences of pediatricians and family physicians. Am J Prev Med 2004; 26:11-4; PMID:14700706; http://dx.doi. org/10.1016/j.amepre.2003.09.004
14. Kempe A, Daley MF, McCauley MM, Crane LA, Suh CA, Kennedy AM, Basket MM, Stokley SK, Dong F, Babbel CI, et al. Prevalence of parental concerns about childhood vaccines: the experience of primary care physicians. Am J Prev Med 2011; 40:548-55; PMID:21496754; http://dx.doi.org/10.1016/j. amepre.2010.12.025

15. Larson HJ, Smith DM, Paterson P, Cumming M, Eckersberger E, Freifeld CC, Ghinai I, Jarrett C, Paushter L, Brownstein JS, et al. Measuring vaccine confidence: analysis of data obtained by a media surveillance system used to analyse public concerns about vaccines. Lancet Infect Dis 2013; 13:606 13; PMID:23676442; http://dx.doi.org/10.1016/ S1473-3099(13)70108-7

16. Ball LK, Evans G, Bostrom A. Risky business: challenges in vaccine risk communication. Pediatrics 1998; 101:453-8; PMID:9481013; http://dx.doi. org/10.1542/peds.101.3.453

17. Orenstein WA, Hinman AR. The immunization system in the United States - the role of school immunization laws. Vaccine 1999; 17(Suppl 3):S1924; PMID:10559531; http://dx.doi.org/10.1016/ S0264-410X(99) 00290-X

18. Vaccine Exemptions. Johns Hopkins Bloomberg School of Public Health - Institue for Vaccine Safety, 2012.

19. Rota JS, Salmon DA, Rodewald LE, Chen RT, Hibbs BF, Gangarosa EJ. Processes for obtaining nonmedical exemptions to state immunization laws. Am J Public Health 2001; 91:645-8; PMID:11291383; http://dx.doi.org/10.2105/AJPH.91.4.645

20. Omer SB, Pan WK, Halsey NA, Stokley S, Moulton LH, Navar AM, Pierce M, Salmon DA. Nonmedical exemptions to school immunization requirements: secular trends and association of state policies with pertussis incidence. JAMA 2006; 296:175763; PMID:17032989; http://dx.doi.org/10.1001/ jama.296.14.1757

21. Omer SB, Richards JL, Ward M, Bednarczyk RA Vaccination policies and rates of exemption from immunization, 2005-2011. N Engl J Med 2012. 367:1170-1; PMID:22992099; http://dx.doi. org/10.1056/NEJMc1209037

22. Centers for Disease Control and Prevention (CDC). Vaccination coverage among children in kindergarten--United States, 2011-12 school year. MMWR Morb Mortal Wkly Rep 2012; 61:647-52; PMID:22914226

23. Washington State Department of Health. School Immunization Status Data Reports. 2012.

24. Ernst KC, Jacobs ET. Implications of philosophical and personal belief exemptions on re-emergence of vaccine-preventable disease: the role of spatial clustering in under-vaccination. Hum Vaccin Immunother 2012; 8:838-41; PMID:22508414; http://dx.doi. org/10.4161/hv.19743

25. Smith PJ, Chu SY, Barker LE. Children who have received no vaccines: who are they and where do they live? Pediatrics 2004; 114:187-95; PMID:15231927; http://dx.doi.org/10.1542/peds.114.1.187
26. Glanz JM, McClure DL, Magid DJ, Daley MF, France EK, Salmon DA, Hambidge SJ. Parental refusal of pertussis vaccination is associated with an increased risk of pertussis infection in children. Pediatrics 2009; 123:1446-51; PMID:19482753; http://dx.doi.org/10.1542/peds.2008-2150

27. Birnbaum MS, Jacobs ET, Ralston-King J, Erns KC. Correlates of high vaccination exemption rates among kindergartens. Vaccine 2013; 31:750 6; PMID:23246263; http://dx.doi.org/10.1016/j. vaccine.2012.11.092

28. Kim SS, Frimpong JA, Rivers PA, Kronenfeld JJ. Effects of maternal and provider characteristics on up-to-date immunization status of children aged 19 to 35 months. Am J Public Health 2007; 97:259 66; PMID:17194865; http://dx.doi.org/10.2105/ AJPH.2005.076661

29. Smith PJ, Humiston SG, Marcuse EK, Zhao Z, Dorell CG, Howes C, Hibbs B. Parental delay or refusal of vaccine doses, childhood vaccination coverage at 24 months of age, and the Health Belief Model. Public Health Rep 2011; 126(Suppl 2):135-46; PMID:21812176

30. Sugerman DE, Barskey AE, Delea MG, OrtegaSanchez IR, Bi D, Ralston KJ, Rota PA, WatersMontijo K, Lebaron CW. Measles outbreak in a highly vaccinated population, San Diego, 2008: role of the intentionally undervaccinated. Pediatrics 2010; 125:747-55; PMID:20308208; http://dx.doi. org/10.1542/peds.2009-1653

31. Salmon DA, Moulton LH, Omer SB, DeHart MP, Stokley S, Halsey NA. Factors associated with refusal of childhood vaccines among parents of school-aged children: a case-control study. Arch Pediatr Adolesc Med 2005; 159:470-6; PMID:15867122; http:// dx.doi.org/10.1001/archpedi.159.5.470

32. ASTHO. Communicating Effectively About Vaccines: Summary of a Survey of U.S. Parents and Guardians Arlington, VA: Association of State and Territorial Health Officials, 2010.

33. Freed GL, Clark SJ, Butchart AT, Singer DC, Davis MM. Sources and perceived credibility of vaccinesafety information for parents. Pediatrics 2011; 127(Suppl 1):S107-12; PMID:21502236; http:// dx.doi.org/10.1542/peds.2010-1722P

34. Gaudino JA, Robison S. Risk factors associated with parents claiming personal-belief exemptions to school immunization requirements: community and other influences on more skeptical parents in Oregon, 2006. Vaccine 2012; 30:1132-42; PMID:22178105; http://dx.doi.org/10.1016/j.vaccine.2011.12.006

35. Jones AM, Omer SB, Bednarczyk RA, Halsey NA, Moulton LH, Salmon DA. Parents' source of vaccine information and impact on vaccine attitudes, beliefs, and nonmedical exemptions. Adv Prev Med 2012; 2012:932741; PMID:23082253; http://dx.doi. org/10.1155/2012/932741

36. Salmon DA, Sotir MJ, Pan WK, Berg JL, Omer SB Stokley S, Hopfensperger DJ, Davis JP, Halsey NA. Parental vaccine refusal in Wisconsin: a case-control study. WMJ 2009; 108:17-23; PMID:19326630 
37. Kennedy A, Lavail K, Nowak G, Basket M, Landry $\mathrm{S}$. Confidence about vaccines in the United States: understanding parents' perceptions. Health Aff (Millwood) 2011; 30:1151-9; PMID:21653969; http://dx.doi.org/10.1377/hlthaff.2011.0396

38. Cave S, Mitchell D. What Your Doctor May Not Tell You About(TM) Children's Vaccinations. Grand Central Publishing, 2007.

39. Sears RW. The Vaccine Book: Making the Right Decision for Your Child. Little, Brown, 2011.

40. Wightman A, Opel DJ, Marcuse EK, Taylor JA. Washington State pediatricians' attitudes toward alternative childhood immunization schedules. Pediatrics 2011; 128:1094-9; PMID:22123877; http://dx.doi.org/10.1542/peds.2011-0666

41. Robison SG, Groom H, Young C. Frequency of alternative immunization schedule use in a metropolitan area. Pediatrics 2012; 130:32-8; PMID:22711719; http://dx.doi.org/10.1542/peds.2011-3154

42. National Research Council. The Childhood Immunization Schedule and Safety: Stakeholder Concerns, Scientific Evidence, and Future Studies. The National Academies Press, 2013.

43. Glanz JM, Newcomer SR, Narwaney KJ, Hambidge SJ, Daley MF, Wagner NM, McClure DL, Xu S, Rowhani-Rahbar A, Lee GM, et al. A populationbased cohort study of undervaccination in 8 managed care organizations across the United States. JAMA Pediatr 2013; 167:274-81; PMID:23338829; http:// dx.doi.org/10.1001/jamapediatrics.2013.502

44. Salmon DA, Haber M, Gangarosa EJ, Phillips L, Smith NJ, Chen RT. Health consequences of religious and philosophical exemptions from immunization laws: individual and societal risk of measles. JAMA 1999; 282:47-53; PMID:10404911; http://dx.doi. org/10.1001/jama.282.1.47
45. Feikin DR, Lezotte DC, Hamman RF, Salmon DA, Chen RT, Hoffman RE. Individual and community risks of measles and pertussis associated with personal exemptions to immunization. JAMA 2000; 284:3145-50; PMID:11135778; http://dx.doi. org/10.1001/jama.284.24.3145

46. Glanz JM, McClure DL, O'Leary ST, Narwaney KJ, Magid DJ, Daley MF, Hambidge SJ. Parental decline of pneumococcal vaccination and risk of pneumococcal related disease in children. Vaccine 2011; 29:9949; PMID:21145372; http://dx.doi.org/10.1016/j. vaccine.2010.11.085

47. Glanz JM, McClure DL, Magid DJ, Daley MF, France EK, Hambidge SJ. Parental refusal of varicella vaccination and the associated risk of varicella infection in children. Arch Pediatr Adolesc Med 2010; 164:66-70; PMID:20048244; http://dx.doi. org/10.1001/archpediatrics.2009.244

48. Omer SB, Enger KS, Moulton LH, Halsey NA, Stokley S, Salmon DA. Geographic clustering of nonmedical exemptions to school immunization requirements and associations with geographic clustering of pertussis. Am J Epidemiol 2008; 168:1389-96; PMID:18922998; http://dx.doi.org/10.1093/aje/ kwn 263

49. Katz SL, Hinman AR. Summary and conclusions: measles elimination meeting, 16-17 March 2000. J Infect Dis 2004; 189(Suppl 1):S43-7; PMID:15106088; http://dx.doi.org/10.1086/377696

50. Parker Fiebelkorn A, Redd SB, Gallagher K, Rota PA, Rota J, Bellini W, Seward J. Measles in the United States during the postelimination era. J Infect Dis 2010; 202:1520-8; PMID:20929352; http://dx.doi. org/10.1086/656914
51. Centers for Disease Control (CDC). Tetanus in child with improper medical exemption from immunization--Florida. MMWR Morb Mortal Wkly Rep 1985; 34:550-2; PMID:3929057

52. Stadlin S, Bednarczyk RA, Omer SB. Medical exemptions to school immunization requirements in the United States--association of state policies with medical exemption rates (2004-2011). J Infect Dis 2012; 206:989-92; PMID:22936834; http://dx.doi. org/10.1093/infdis/jis436

53. Sadaf A, Richards JL, Glanz J, Salmon DA, Omer SB. A systematic review of interventions for reducing parental vaccine refusal and vaccine hesitancy. Vaccine 2013; 31:4293-304; PMID:23859839; http://dx.doi.org/10.1016/j.vaccine.2013.07.013

54. Opel DJ, Heritage J, Taylor JA, Mangione-Smith R, Salas HS, Devere V, Zhou C, Robinson JD. The Architecture of Provider-Parent Vaccine Discussions at Health Supervision Visits. Pediatrics 2013; PMID:24190677; http://dx.doi.org/10.1542/ peds.2013-2037 